SAGE Joven es un grupo formado por gastroenterólogos jóvenes con ganas de generar actividades, estrechar lazos y escuchar propuestas.

Conocenos más en: www.sage.org.arlsagejoven

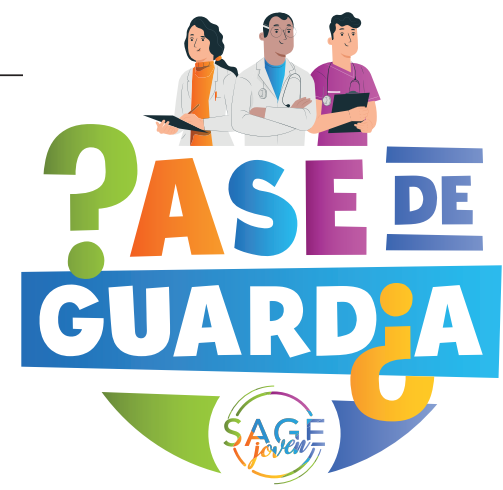

\title{
Las apariencias engañan
}

\section{Carolina Rodríguez Bruno, Evelin Crocci, Ezequiel Balaban, Carla Sofía Ponce}

Residencia de Clínica Gastroenterológica, Hospital Dr. Carlos Bonorino Udaondo. Ciudad Autónoma de Buenos Aires, Argentina.

Acta Gastroenterol Latinoam 2021;51(1):39-40

Recibido: 10/03/2021 / Aceptado: 10/03/2021 / Publicado online: 22/03/2021 / https://doi.org/10.52787/fpkt6323

\section{Caso clínico}

Paciente de sexo femenino de 57 años de edad, con antecedente de litiasis vesicular y lesión hepática en estudio desde hace dos años, que al momento del diagnóstico tenía un tamaño aproximado de $43 \mathrm{~mm}$ por ecografía. Consulta a guardia por cuadro de 12 horas de evolución, caracterizado por dolor abdominal, localizado en epigastrio, tipo cólico de intensidad $8 / 10$, que no cede a la inges-

Correspondencia: Cecilia Carraro

Correo electrónico: cecilia_carraro@yahoo.com.ar ta de antiespasmódicos, irradiado a hipocondrio derecho y dorso, acompañado de náuseas y vómitos de características alimentarias en dos ocasiones. Al examen físico se evidencia como dato positivo un abdomen blando, depresible, doloroso a la palpación superficial y profunda en epigastrio e hipocondrio derecho sin reacción ni defensa. RHA positivos.

Laboratorio: Leucocitosis $13.900 \mathrm{mil} / \mathrm{mm}^{3}$ (neutrófilos 89\%), TGO $257 \mathrm{u} / \mathrm{l}$, TGP $129 \mathrm{u} / \mathrm{l}$, FAL $100 \mathrm{u} / \mathrm{l}$, GGT $182 \mathrm{u} / \mathrm{l}$, Bilirrubina Total 0,28 mg/dl, Amilasa $911 \mathrm{mg} / \mathrm{dl}$, LDH 398 u/l, calcio 9,4 mg/dl, PAFI 376, Albúmina 3,3 mg/dl.

Ecografía (Figura 1): Hígado de forma regular y tamaño conservado. Se visualiza en segmento IV una imagen quística de contenido particulado que mide $69 \mathrm{x}$ $47 \mathrm{~mm}$ (flecha verde). Vesícula de paredes finas y contenido litiásico múltiple. Vía biliar intra y extrahepática no dilatada. Páncreas de características normales.

Tomografía computada con reconstrucción axial de abdomen con contraste oral y endovenoso (Figura 2): En hígado se observa una imagen quística en segmento IV, proyectándose en la cisura falciforme calcificada, de $60 \mathrm{~mm}$ aproximadamente, con contenido hipodenso no complicado (flecha roja). Edema en cuerpo y cola de páncreas. Vesícula multilitiásica. 
Figuras 1. Ecografia

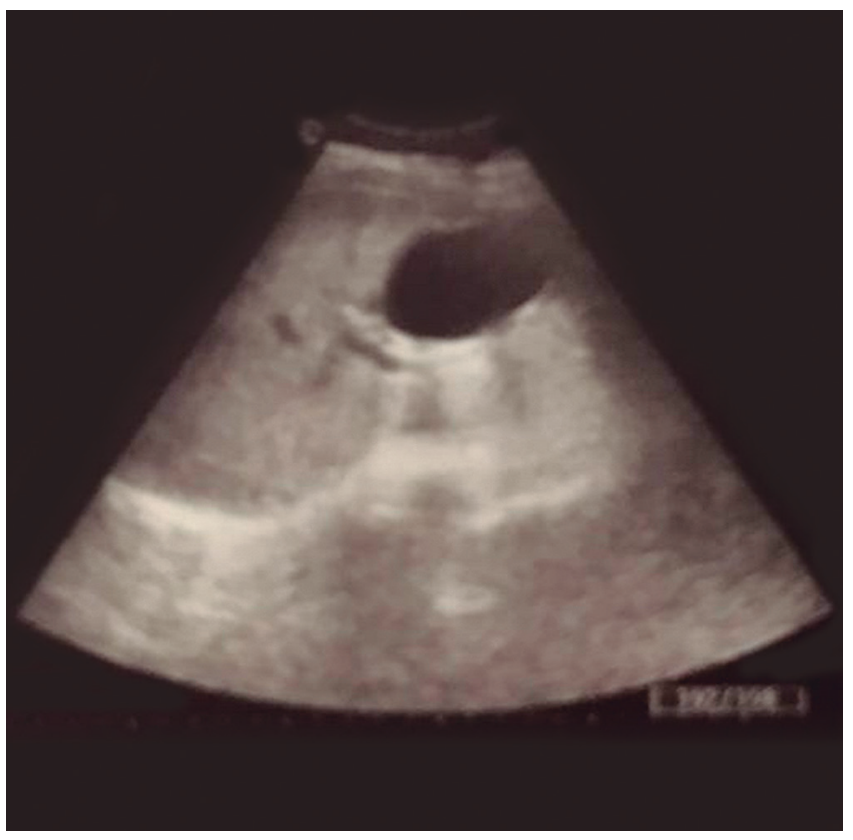

Figuras 2. Tomografía computada con reconstrucción axial de abdomen con contraste oral y endovenoso

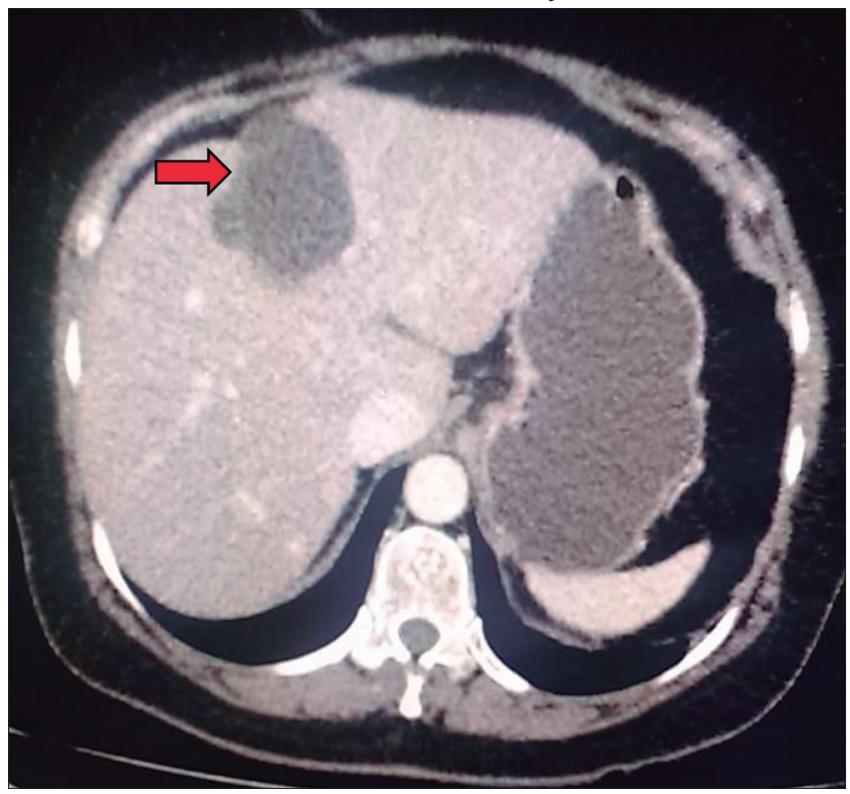

¿Cuál es su impresión diagnóstica?

1. Neoplasia quística serosa.

2. Neoplasia quística mucinosa.

3. Quiste hidatídico.

4. Quiste simple complicado.

Resolución del caso en la página 116 
SAGE Joven es un grupo formado por gastroenterólogos jóvenes con ganas de generar actividades, estrechar lazos y escuchar propuestas.

Conocenos más en: www.sage.org.ar/sagejoven

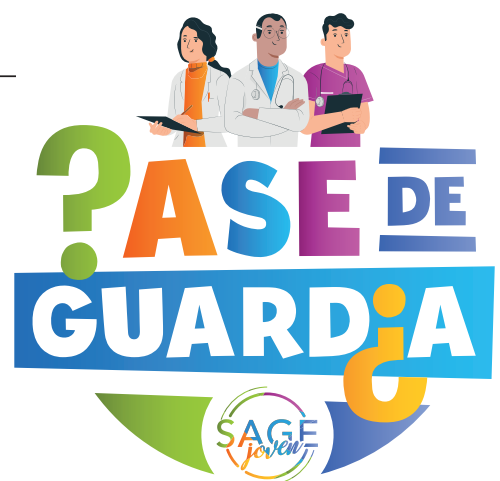

\title{
Solución del caso. Las apariencias engañan
}

\author{
Viene de la página 39
}

\section{Solución del caso}

En el caso presentado se realizó diagnóstico de pancreatitis aguda biliar leve, por lo que se inició tratamiento médico, con buena respuesta. Al interpretar que la lesión hepática en estudio no presentaba síntomas, se decidió llevar a cabo conducta quirúrgica por el rápido aumento del volumen del quiste.

Se recibió resultado de anatomía patológica compatible con neoplasia quística mucinosa. En la figura 1 se muestra la imagen macroscópica de la lesión quística multiloculada con superficie interna lisa. En la figura 2 podemos observar la pared revestida por epitelio mucinoso y estroma ovárico. En la figura 3 se observa la inmunomarcación positiva para receptores de estrógeno y progesterona.

\section{Figura 1}

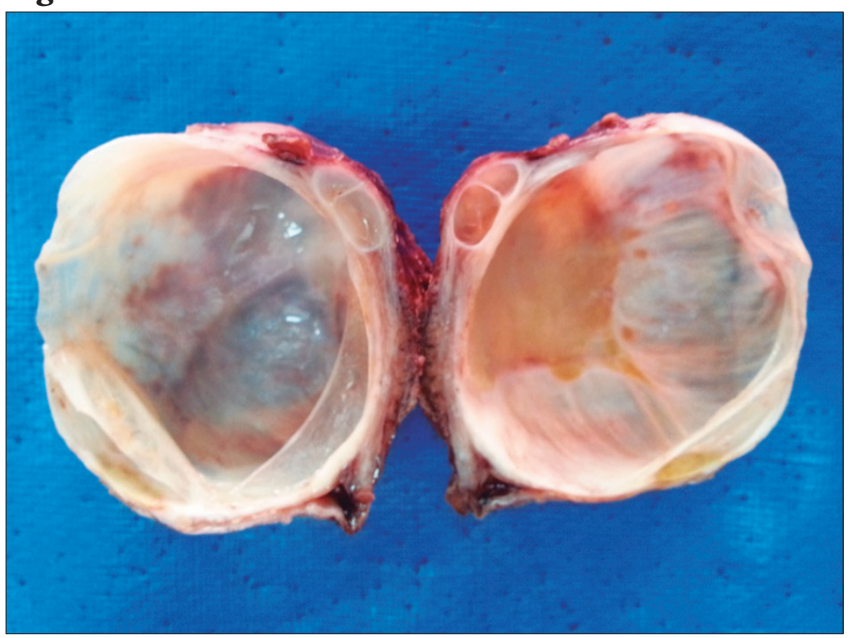

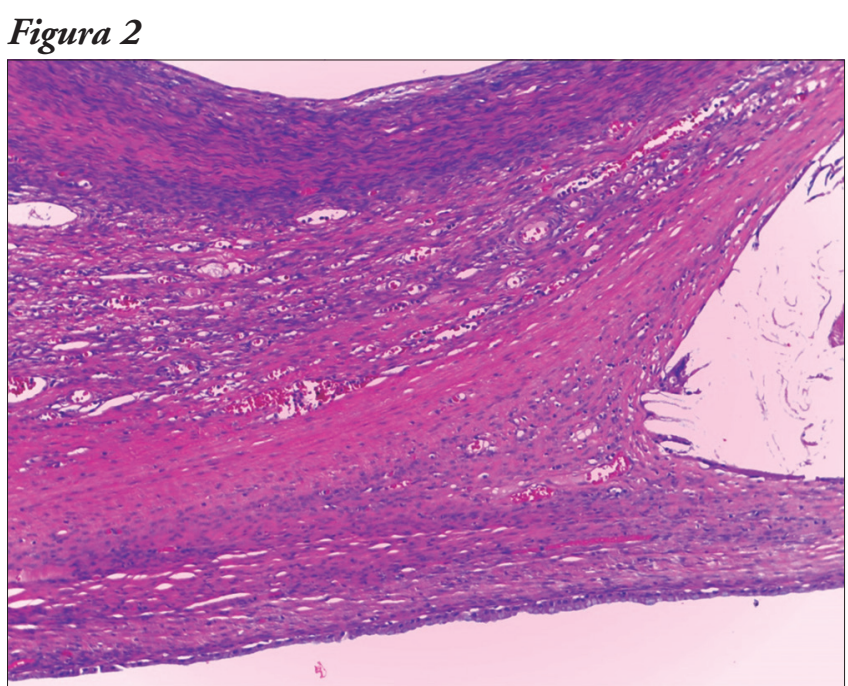

\section{Figura 3}

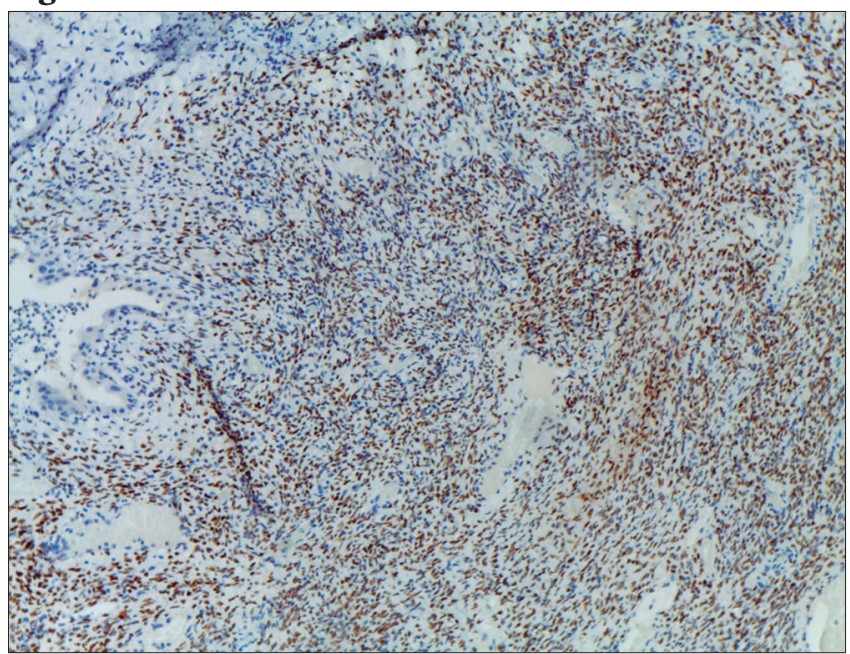


Las lesiones hepáticas focales son una causa frecuente de consulta, por lo que es necesario realizar un diagnóstico certero en el menor tiempo posible para así poder dirigir el tratamiento. El enfoque debe ser multidisciplinario ya que la resolución de estos casos muchas veces requiere intervención quirúrgica. ${ }^{1,2}$

Los estudios por imágenes son, junto con una detallada anamnesis, el método complementario más importante para la valoración y el diagnóstico diferencial de estas lesiones.

Las lesiones hepáticas focales se clasifican en sólidas y quísticas. Dependiendo de sus características imagenológicas, estas últimas se subdividen en simples y complejas. Las imágenes focales quísticas simples se caracterizan por ser menores a $1 \mathrm{~cm}$ (pueden presentar diámetros de hasta $30 \mathrm{~cm}$ ), de contenido homogéneo y paredes bien definidas. En contraposición, los quistes complejos presentan contenido heterogéneo, tabiques internos, engrosamiento de la pared, lobulaciones, y refuerzo posterior a la inyección de contraste. ${ }^{2}$

Ante la presencia de una lesión quística compleja, se plantean como diagnósticos diferenciales el quiste hidatídico, el quiste seroso y la neoplasia quística mucinosa. En segunda instancia se encuentran el quiste simple complicado y el absceso hepático.

Los tumores quísticos mucinosos son lesiones neoplásicas benignas poco frecuentes. Clínicamente se manifiestan de forma inespecífica e insidiosa en relación con el grado de invasión y el efecto de masa tumoral, siendo el dolor abdominal el síntoma más frecuente. Si bien el diagnóstico definitivo es anátomo-patológico, los estudios de imágenes tienen un gran valor. El gold standard en esta categoría es la resonancia magnética nuclear, aunque, debido a su mayor accesibilidad y disponibilidad, la ecografía y la tomografía contrastada se emplean con más frecuencia. $\mathrm{Al}$ análisis anatomopatológico se reconoce un epitelio de tipo columnar que puede o no ser secretor de mucina. ${ }^{3}$
El tratamiento de esta lesión es quirúrgico, dada la posibilidad de progresión a la malignidad y la aparición de recidivas en caso de escisión incompleta, y se indica en los casos sintomáticos. Los procedimientos de elección son la enucleación y la resección hepática por sobre la marsupialización, el drenaje interno, la aspiración y la resección parcial. ${ }^{3}$

\section{Aviso de derechos de autor}

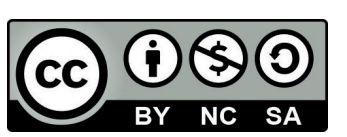

(C) 2021 Acta Gastroenterológica Latinoamericana. Este es un articulo de acceso abierto publicado bajo los términos de la Licencia Creative Commons Attribution (CC BY-NC-SA 4.0), la cual permite el uso, la distribución $y$ la reproducción de forma no comercial, siempre que se cite al autor y la fuente original.

Cite este artículo como: Rodríguez Bruno C, Crocci E, Balaban Ey col. Las apariencias engañan. Acta Gastroenterol Latinoam. 2021;51(1):39-40, 116-7. https://doi.org /10.52787/fpkt6323

\section{Referencias}

1. Mavilia MG, Pakala T, Molina M, Wu GY. Differentiating cystic liver lesions: a review of imaging modalities, diagnosis and management. J Clin Transl Hepatol. 2018;6(2):208-16.

2. Marrero JA, Ahn J and Rajender Reddy K. ACG Clinical Guideline: The Diagnosis and Management of Focal Liver Lesions. The American Journal of Gastroenterology. 2014;109:1328-47.

3. Mezale D, Strumfa I, Vanags A, Bahs G, Strumfs B, Silovs A, Riekstins R, Gardovskis J. Mucinous Cystic Neoplasms of the Liver and Extrahepatic Biliary Tract. Topics in the Surgery of the Biliary Tree, capítulo 6. 